\title{
The role of the alternative relation in cognition and the disjunctive conjunctions as a means of its verbalization
}

\author{
Natalia Sklyarova ${ }^{1 *}$ \\ ${ }^{1}$ Don State Technical University, Gagarin square, 1, Rostov-on-Don, 344000, Russia
}

\begin{abstract}
The cognitive processes of the human mind are not perceived directly, the information about them can be received through the analysis of their representation in the language means. The article is devoted to the cognitive study of the English syntactic structures with the disjunctive conjunctions used in speech, in the contextual environment. The inherent meaning of alternative which these conjunctions possess is modified under the influence of the lexical-grammatical context. It makes the English syntactic structures containing these conjunctions applicable not only for the description of the situation of choice, but also for the depiction of the situations of deficient knowledge, alternation, distribution, motivation. Due to the neutralization of the inherent meaning of the conjunctions in the context the constructions which contain them can convey in English such mental operations as enumeration, approximation and addition. The analysis of English syntactic structures with the conjunctions reveals the cognitive work of the human mind. The results of the research are useful for the English language acquisition as the syntactic structures with the disjunctive conjunctions help the speaker to achieve the variety of communicative goals.
\end{abstract}

\section{Introduction}

The cognitive approach has become widespread in linguistics as on the one hand it enables to understand better and interpret correctly various language phenomena, on the other hand, the mental operations of our mind are not directly observable, but one can get the information about them analyzing language phenomena. The theoretical and methodological issues of cognitive linguistics have been discussed in the works of Russian $[1,2]$ and foreign scholars $[3,4]$ who contributed to its development as an interdisciplinary science. Nowadays, the cognitive approach is used in the studies devoted to European languages, such as English [5, 6], German [7], Hungarian [8], which differ considerably in their structure. Thanks to the latest achievements in cognitive linguistics the regularities and peculiarities in the creation of language units of the morphological, lexical, and syntactic levels were singled out. The cognitive approach is applied in the exploration of various

\footnotetext{
*Corresponding author: panochka@bk.ru
} 
processes, categories, and units of the language, such as phrasal verbs [5], word building means, including affixation [9] and contamination [10], semantic changes [11], morphological categories [6], syntactic models of simple sentences [12], interrogative structures [13]. The results of these studies show various forms of the interconnection between mind and language, display the role of language phenomena in cognition. The cognitive methodology has been transferred to the investigation of bilinguals [14], native and foreign language acquisition [15], translation and interpretation [16], which provides us with innovative methods of teaching languages [17]. Cognitive research of different types of discourse, namely, political [18] media [19] and advertising [20], has also become popular as it helps to find out the mental mechanisms of manipulative strategies and use them effectively or, on the contrary, resist them.

However, the English syntactic structures with the disjunctive conjunctions have not been analyzed from this point of view yet, though the alternative relation expressed by them plays a significant role in the cognition of reality.

The goal of this article consists in the classification and description of various situations and mental operations which are conveyed in English by the syntactic structures with the disjunctive conjunction. It will show the importance of the alternative relation in the comprehension of reality and the role of English disjunctive conjunctions in depicting it. It will also help to estimate the significance of English syntactic structures with the disjunctive conjunction for the communicative purposes and to emphasize the necessity of giving special attention to them while teaching English. The research is based on the general ideas of cognitive linguistics presented in the works of N. Boldyrev [1,2] as well as on the cognitive principles of semantic syntax developed by K. Fischer [3].

\section{Materials and methods}

The goal and the tasks of the research has determined the selection of methods applied in it. The cognitive approach to the language units presumes the investigation of their meaning in connection with the activity of the human mind. The disjunctive conjunctions of the English language are described in their interaction with the contextual environment by means of the distributional analysis. To differentiate certain types of situations and mental operations expressed by the English syntactic structures with the disjunctive conjunction the transformational analysis is used. The statistical method shows the frequency of usage of the English disjunctive conjunctions in different contextual meanings.

To illustrate various types of situations comprehended or interpreted by means of the alternative relation and rendered in the English language by means of the syntactic structures with the disjunctive conjunctions the examples from the collection of the British National Corpus [21] and the Corpus of Contemporary American [22] are used. The authenticity of the sources contributes to the objectivity and genuineness of the results.

The study includes the following stages:

- to state the essence of the relation in general, and the epistemological nature of the alternative relation.

- to determine the prototypical situation reproduced in the picture of the world by means of the alternative relation and expressed in the English language by the syntactic structures with the disjunctive conjunctions.

- to distinguish other types of situations reproduced in the picture of the world by means of the alternative relation and conveyed in the English language by the syntactic structures with the disjunctive conjunctions.

- to describe the lexical-grammatical context in which the inherent meaning of the English disjunctive conjunction is modified due to the type of the situation comprehended or interpreted by the human mind by means of the alternative relation. 
- to identify the mental operations of the speaker conveyed in the English language by means of the syntactic structures with the disjunctive conjunctions.

- to characterize the lexical-grammatical context in which the inherent meaning of the English disjunctive conjunction is neutralized due to the type of the mental operation carried out by means of the alternative relation.

\section{Results}

The relation is defined as an existing connection, a significant association between or among things. Most types of relations are epistemological in nature since they are not found in the surrounding world, they appear in the human mind being the result of its comprehension of reality. The main function of relations consists in joining things, qualities, actions in the picture of the world created by the human mind. Thus, people cognize the environment by determining the types of relations between its objects and phenomena. The human mind distinguishes various types of relations, those of condition, cause, comparison, concession, alternative.

It is universally accepted that the information which is perceived and processed by the brain finds its expression in the language units. According to the general characteristics of the formal words, conjunctions belong to the language means which nominate the type of relation of one object or phenomenon to another. Uniting words, phrases and sentences in speech conjunctions indicate the type of relation with the help of which human mind connects different objects and phenomena of reality expressed by these words, phrases, and sentences. Since the relation is impossible without related objects and phenomena the meaning of conjunctions denoting any type of relation presupposes the presence of other language means, denoting the related objects and phenomena. Indeed, conjunctions taken separately have the meaning of their own, but it is rather ambiguous and generalized. While a conjunction is used in speech its meaning is specified and modified under the influence of the lexical-grammatical environment. So, the meaning of conjunctions depends on the context, or in other words, conjunctions possess inherent features whereas in the utterance they acquire contextual features.

The essence of the alternative relation is revealed through the observation of everyday life. In all its spheres there regularly occur circumstances when certain things happen to be mutually exclusive. Such things are related to one another by the human mind as alternative. Mutual exclusiveness has different reasons which in their turn are determined by various kinds of incompatibility, such as logical, temporal, locative, social, ethical. Thus, the alternative relation appears in the human mind as a result of its comprehensive activity which consists in connecting certain objects and phenomena to each other. In other words, the alternative relation exists in the picture of the world created in the mind. The cognitive process is impossible without a language which fixes its results. The English language means conveying the alternative relation are the disjunctive conjunctions or, either... or. They form the syntactic structures uniting words, phrases and sentences which denote simple and complex situations considered by people as mutually exclusive. The disjunctive conjunctions are regarded one of the universal types of coordinators as they are found in all European languages. It is probably determined by the role of the alternative relation in cognitive processes of the human mind.

There exists the interdependence between the picture of the world which exists in the mind and the language units which depict it. On the one hand, the way we describe the reality depends on the way we comprehend it; on the other hand, the comprehension of the reality is partially determined by the language structure.

Our research reveals the same interdependence between the alternative relation which the human mind distinguishes cognizing the surrounding world and the English disjunctive 
conjunctions which provide the syntactic connection between elements of the sentence denoting the related objects and phenomena. The human ability to interpret various types of situations and carry out various mental operations by means of the alternative relation can be explained by the modification or neutralization in the meaning of the corresponding English conjunctions which occur the context under the influence of their lexical and grammatical environment. At the same time, thanks to this modification and neutralization various situations and mental operations can be interpreted by means of the alternative relation.

The statistical analysis of about 3000 sentences with the disjunctive conjunctions taken from the authentic English sources shows that the regularity in the usage of the constructions with the disjunctive conjunctions for the depiction of the situations and mental operations varies considerably (See Table 1):

Table 1. The usage frequency of the disjunctive conjunctions in various contextual meanings.

\begin{tabular}{|c|c|}
\hline situation / mental operation & data \\
\hline choice & $7,26 \%$ \\
\hline deficient knowledge & $19,67 \%$ \\
\hline alternation & $3,44 \%$ \\
\hline distribution & $2,63 \%$ \\
\hline motivation & $1,99 \%$ \\
\hline enumeration & $27,76 \%$ \\
\hline approximation & $26 \%$ \\
\hline addition & $11,25 \%$ \\
\hline
\end{tabular}

The data show that the mental operations of enumeration and approximation are verbalized most frequently which can be explained by their greater importance for the communication, while the situations of motivation, distribution and alternation are verbalized least frequently though it does not mean that they seldom occur.

\section{Discussion}

The analysis of the extensive language material enables us to single out five types of situations comprehended by the human mind and represented in the picture of the world by means of the alternative relation as well as three types of mental operations carried out by the human mind cognizing the reality by means of the alternative relation. They are rendered in English by means of the syntactic structures which consist of language elements of various complexity joined by the disjunctive conjunctions.

\subsection{The situation of choice}

The alternative is defined as the choice between several mutually exclusive opportunities. The situation when a person is supposed to make this choice is comprehended by the human mind and represented in the picture of the world by means of the alternative relation and is regarded prototypical. The necessity to choose can be determined by various objective or subjective factors, namely, ontological restrictions, social laws and rules, logical incompatibility, scarce productive and consuming abilities, the system of human values, as well as the combination of such factors. The decision to choose one or another opportunity is based on personal goals and ambitions, ideals and moral principles, preferences and conventions, physical, mental, financial abilities, inner impulses, and outer circumstances. 
Representing the situation of choice, the English disjunctive conjunctions may interact in speech with such language units as: the verbs to opt for, to choose, to decide, to pick; the nouns choice, decision, alternative, option, possibility, opportunity which explicitly convey the necessity for a person to choose. For example:

The annexation offered the inhabitance of our province two choices: to leave and retain their French nationality or to remain but to take German nationality Choose. Either your destination or your direction [21]. I was going to tell Spark he had a choice. He could be a son of a bitch. Or else he could cooperate [22].

In the following sentences the necessity of choice is conveyed implicitly in such phrases as: to be free to, to be torn between:

She was free to make changes or else to live as she had always lived. I had been torn between spending the last twelve dollars on some dried fruit or an extra bag of rice [21].

In the case of absence of any contextual means one should analyze extralinguistic background to distinguish the situation of choice from others. In the following two sentences the situation of choice is described. The necessity of choice in the first case is determined by the impossibility for an individual to be in different places simultaneously, while in the second case it is determined by the difficulty to combine several jobs:

We can take you with us to Mallorca or drop you here [21].

- How did she become a cop? - It was either that or teaching in the high school where senior kids didn't feel like learning French [22].

The following English set expressions with the disjunctive conjunctions are also used to describe the situation of choice: end or mend; fish or cut bait; hit or miss; make a spoon or spoil the horn; make or break; neck or nothing; now or never; root hog or die; sink or swim; stand or fall. For example:

Again, change was in the air; the chance had to be seized; it was now or never. She received this job and now this was a matter of sink or swim [21]. With women, you got $t^{\prime}$ fish or cut bait. In a sense, it was a make-or-break decision [22].

\subsection{The situation of deficient knowledge}

The situation of deficient knowledge is interpreted by the human mind and reproduced in the picture of the world by means of the alternative relation. In such cases it is known that only one of several events occurred, is occurring or will occur, but is still unknown which one because the speaker does not have enough information due to its unavailability, unreliability, imprecision, vagueness. The deficient information is accompanied by the hypothetic type of modality which is conveyed in English by the verbs denoting mental activity to assume, to believe, to consider, to suppose, to think, and/or by the words of different parts of speech with the suppositional meaning, such as: the modal words absolutely, actually, apparently, certainly, definitely, evidently, indeed, maybe, naturally, obviously, perhaps, possibly, probably, surely, undoubtedly, the modal verbs can, may, must, should, ought and their equivalent have to; the nouns and adjectives possible, possibility, probable, probability, obvious, evident, natural. The language units mentioned above modify the inherent meaning of the disjunctive conjunctions enabling them to convey the situation of deficient knowledge.

Comparing the situation of deficient knowledge with the situation of choice one can discover similarity in the reasons of mutual exclusiveness of events in question, in particular:

- logical incompatibility owing to the contrary nature of objects or phenomena, which is expressed by the language units with the opposite meanings or is seen from the context. For example:

Soon he must either be drowned or get to shore. He was killed off or died in 1925 [21]. 
- temporal and/or locative incompatibility owing to the impossibility for one and the same object to be in several places simultaneously. For example:

As the murders began in April this year, the killer may have been recently released from a mental hospital or prison. I assumed he lived closer to Quantico, perhaps in Alexandria or Mclean [22].

- quantitative or qualitative incompatibility owing to the characteristic features of the material world. For example:

The size of the suit she is wearing is large or perhaps extra-large. The substance on the murdered women's bodies could be a crystal carbonate or a sodium nitrate [22].

- social incompatibility owing to the social factors. For example:

She may be a businesswoman or doctor or lawyer, and often wears suits of bright colors [22].

\subsection{The situation of alternation}

The situation of alternation is interpreted by the human mind and reproduced in the picture of the world by means of the alternative relation. In this case several events take turns, excluding each other in such a way that when one event occurs the other does not and vice versa. The sentences with the disjunctive conjunction, describing such situations are characterized by the presence of different English language units. According to our previous research [23], they include different dates, the names of seasons, days of the week, months, the word combinations with the prepositions before, after, during; the temporal adverbial clauses, introduced by the conjunctions after, before, while, when, till, until, and the adverbs denoting indefinite time always, sometimes, often, seldom, from time to time. These language units function separately or in combinations, stating the period and/or interval of alternation. They modify the inherent meaning of the disjunctive conjunctions enabling them to convey the situation of alternation. For example:

Mrs. Cornwell usually sent her niece a handmade table centre or an embroidered handkerchief case at Christmas. During the hottest part of the day, I would wander to the creek or just lie in the shadow watching the sky through the trees. So, while her husband was busy with the papers Ruth either played with their son or just read to herself [21]. Every Saturday morning Tracy jogged on the promenade or along the West River Drive [22].

\subsection{The situation of distribution}

The situation of distribution is interpreted by the human mind and reproduced in the picture of the world by means of the alternative relation. In this case qualities, actions and even entire events are distributed between inanimate or animate objects in the mutually exclusive way. It means that some of these objects fulfill certain actions, possess certain qualities, or are involved into certain events, while other qualities, actions, events are attributed to other objects. The sentences with the disjunctive conjunctions, describing such situations are characterized by the presence of different English language units. According to our previous research [23], they include collective nouns, substantivized participles, and adjectives, the third person plural personal pronoun, the pronoun everybody; plural class nouns with or without preceding cardinal numerals. They are used as the subject of the sentence as well as in the constructions with secondary predication. They may also be secondary members in the principal clause serving the antecedent to which the subject of the subordinate clause refers. These language units modify the inherent meaning of the disjunctive conjunctions enabling them to convey the situation of distribution. For example: 
The clinic staff spent the weekend driving to the north, to the capital, or to one of the big dams. Sometimes he would approach a passer-by to ask the question which tormented his sick mind and the questioned would pass by without a word turning back in fear or mutter something inarticulate [21]. But when everything settled down, they returned to the university or to the father's construction or oil company, or his bank, or got married. I realized that on Friday night everybody was home for the weekend or out with their dates. Appointments, lectures, and demonstration autopsies had been canceled or pushed weeks ahead. Six people were found dead without shoes and socks either inside the abandoned cars or in the woods [22].

\subsection{The situation of motivation}

The situation of motivation is interpreted by the human mind and reproduced in the picture of the world by means of the alternative relation. In this case some action is encouraged by possible consequences either actual or exaggerated which may take place if this action is not fulfilled. The motivated action is described in the part of the utterance preceding the disjunctive conjunction, while the motivating consequences are mentioned in the part following the disjunctive conjunction. Thus, the condition contrary to the action expressed in the first part of the utterance is implied. For example:

I've got to escape from here or [if I don't escape from here] I won't survive [22].

In both parts of the sentence the forms of the predicate modify the inherent meaning of the disjunctive conjunctions enabling them to convey the situation of motivation. The predicate preceding the conjunction contains verbs in the imperative mood, the modal verbs must, should, have to, can, the construction with the modal meaning to be going to. These English language means express intention, necessity, obligation, prohibition, recommendation, suggestion to fulfill an action, which is rendered by the following nonfinite verb. The predicate following the conjunction contains verbs in the subjunctive or indicative mood in the latter case they are used in the present tenses denoting future actions or in one of the future tenses. It may also contain the construction with the modal meaning to be going to or the modal verbs expressing possibility, probability. These English language means convey potential events. For example:

Calm down immediately and go on working or I'll kill you. We had better stop it or Madam will be frustrated [21]. You've got to stop blaming me for what has happened or we're going to quarrel. It's got to continue the way I planned or I'm disappointed. We should drive as quickly as possible, or we might be late. You can't miss this chance, or you won't see him again [22].

\subsection{The mental operation of enumeration}

The elements of the sentence united by the disjunctive conjunction may denote objects and phenomena which are in no respect mutually exclusive, thus the human mind uses the alternative relation for enumeration just to bring together the elements of the world picture. It does not mean though that the functional difference between the disjunctive and copulative conjunctions is completely neutralized, as the usage of or implies the continuation of enumeration while and indicates its completion. The operation of enumeration is marked in the English language by the indicators for example, like, such as. For example:

I prefer to do by hand such things as kneading dough or making pasta. The clairvoyant saw a woman who is associated with strong dark colors like red or burgundy or navy [22].

The transformational analysis is very helpful when it is impossible to explain linguistic facts otherwise. Our previous research [23] shows that in those cases when the contextual 
indicators are absent one can distinguish enumeration from choice by means of the substitution of the disjunctive conjunction or by the copulative conjunction and which is sometimes accompanied by changes in the grammatical structure of the sentence. For example:

He remembered facts particularly of an anthropological, geographical, or zoological nature [21] $\rightarrow$ He remembered facts particularly of an anthropological, geographical, and zoological nature.

It was not in the cabinet or in the desk $\rightarrow$ It was not in the cabinet and it was not in the desk [22].

The enumeration combined with condition or concession is expressed in the corresponding clauses. For example:

He wouldn't be surprised if she had been offended or if she had wept or if she had made him a scene, but her calmness scared him. He doesn't care whether I'm improvising or playing from memory or reading notes [21].

\subsection{The mental operation of approximation}

Another mental operation of the human mind performed by means of the alternative relation is approximation. Approximation consists in the inexact identification of extralinguistic reality due to many reasons, in particular, the speaker's dissatisfaction with the vocabulary of the language for naming certain things, ambiguous and obscure perception of the object, deliberate vague and imprecise depiction of the situation due to the rules of etiquette, the lack of appropriate background knowledge, carelessness of the speaker, absence in the speaker's vocabulary of the exact word to express a certain idea. The approximated elements of the world picture are depicted in the English syntactic structures with the disjunctive conjunctions where the position after the conjunction is occupied by the following English words and word combinations conveying the idea of indefiniteness: better, however, less, more, older, so, somelany (of, other) + noun, somebody/anybody (else), someone/anyone (else), something/anything (else, similar, of that kind, like that, etc.), somewhere/anywhere (else), the likes, whatever, whoever, worse. The position before the disjunctive conjunction is occupied by the language units indicating the thing, action, quality, quantity, and event which is close to or resembles the approximately characterized phenomenon. In this case the inherent meaning of the disjunctive conjunctions is neutralized. For example:

He made a pace or so and stopped [21]. The doctor warned her that it can result in apoplexy or worse [22].

The indefinite pronoun something (anything in interrogative and negative sentences) is multifunctional as it is applied for the approximate characteristics of things, quantities, qualities, actions and even the whole events. For example:

She has a salad or something for dinner. You'd think it was an earthquake or something [21]. It was a cheap wristwatch you could get for fifteen dollars or something. My aunt wasn't superstitious or anything, but she believed that things meant to be. For certain reasons the girls at school were sort of ignoring her or something [22].

The indefinite pronoun something is also used to underline that somebody else's speech is not quoted word for word. For example:

There it was written that 'the delicate balance between body and mind makes a personality. The balance between female and male is delicate in each personality' or something like that [21].

The functions of other above-mentioned language means neutralizing the alternative relation expressed by the disjunctive conjunction are restricted. Thus, the indefinite pronouns somebody/anybody (else), someone/anyone (else) can be combined only with 
nouns denoting animate objects, the adverbs so, less, more serve for the approximate characteristics of quantity, the adjectives in the comparative degree worse and better are used for the approximate description of qualities and things. For example:

She considered me to be crazy or worse. I believe he is just a crook or worse. [21].

Some English set expressions with the disjunctive conjunction are also used for the approximation, in particular, more or less, sooner or later, the former having the wide range of application as it is capable of approximate evaluation of things, qualities, and actions. For example:

She will get married and leave her mother sooner or late. As far as I see it, he was more or less of a connoisseur. Your hair must be more or less the same length to style it in this way [21]. I understand your point more or less [22].

The quantitative approximation is the most widespread type as the amount or number always causes difficulties in comprehension and recollection. The object of the quantitative approximation is usually time, distance, weight, price, age. In this case the disjunctive conjunction joins two ordinal numerals marking the borders where the exact quantity is to be found or the disjunctive conjunction joins an ordinal numeral which marks the initial, final, or intermediate point and the adverb more, less, so. For example:

Your coffee will be ready in three minutes or so, sir. She looked thirty or more [21]. The abstract is supposed to contain two hundred words or less. The box was the size of a microwave oven and weighed eight or ten pounds [22].

\subsection{The mental operation of addition}

Finally, the mental operation of the human mind performed by means of the alternative relation is addition. It is verbalized by means of the disjunctive conjunction which adds the word, word combinations or sentence. Additional information is not intended in advance. That is why in writing it is separated from the previous text by the punctuation mark (comma, dash, full stop, dots, brackets), suggesting the pause the speaker makes to think it over. For example:

She handed me ninety milliliters, or less than three ounces, of transparent liquid. She spent two hours reading. Or trying to read as her roommates' conversation distracted her [21].

The word, word combination or sentence introduced by the disjunctive conjunction may be also accompanied by a ready-made or spontaneous language unit indicating that it is a reformulation of what has previously been said. Some of them (rather, at least, I should say, better, if you prefer) emphasize that the information introduced by the disjunctive conjunction is preferable or more reliable than that, conveyed before. For example:

I want to tell you about my aunt - or rather great-great-aunt [21]. According to the report, Mr. Bleibner checked in the hotel, or at least somebody with his passport did. The police wouldn't, or I should say they couldn't, ignore the emergency call. I just advise you to stay away from him, or better put, avoid his company. Margaret was slender - or, if you prefer, fragile [22].

Other contextual markers accompanying the word, word combination or sentence, introduced by the disjunctive conjunction refer to the source and/or to the change in the style of communication, namely individual, literary, official, colloquial, professional, etc. For example:

I bought a pack of cigarettes or 'cancer sticks' as my husband called them. In the lobby of the Chief Medical Examiner's Office, or CMEO, the victim's relatives were waiting for me. The plants wither or - to be poetic - gave up the struggle to survive. I made my way to the laminar flow room, or a bubble, as most people call it [22]. 
The mental operation of addition may serve for correction and explanation. Correction is determined by the dissatisfaction of the speaker with his previous statement due to its improper, inexact, or inaccurate depiction of reality. In other words, with the help of correction the world picture is updated. The correction may cover the following aspects:

- entire event. For example:

We've broken up. Or rather, he's abandoned me [21].

- details of the event (things, qualities, actions). For example:

Then we heard another noise. Or knock [22]. Paul didn't remember her looking more attractive - or more seductive. Sir Henry sat with a smile on his face stroking his moustache - or rather twisting it [21].

- features of things, qualities, and actions (mood, degree, number, time, modality). For example:

I didn't approve of this cooperation - or wouldn't have if I'd had been informed about it. A couple of days after illness she spent in a horizontal - or mostly horizontal - position. [21] The person - or persons involved in these homicides will be brought to justice sooner or later. It is obvious they can't support him. Or not all of them They found out that he was a liar, or they pretty soon will. He drove through the district admiring the new buildings that had been erected - or were still being erected. She did everything to help him overcome this addictive habit. Or almost everything. He left for Paris. Or at least he is supposed to [22].

The correction may also be carried out through stating the authorship when the reliability of the presented facts is questioned. For example:

She had never met him before - or at least this was what she claimed [22].

The accuracy of the reported information may be also improved by means of particularization and generalization. For example:

$\mathrm{He}$ is reported to be an American - or Texan. Her clothes were torn with the knife or some sharp instrument [22].

In case of explanation the speaker believes that his interlocutor does not possess enough background knowledge to understand the message. In other words, the aim of explanation is to adapt the speaker's picture of the world for the listener's intellectual level. It mostly happens with foreign words, scientific terms, words of professional jargons, abbreviations. They are explained by a synonym or periphrasis; the unfamiliar word may occupy the position before or after the conjunction. For example:

The natives use it to make rattles or 'kulaps' for the traditional dancing [21]. In a climate like North Carolina's, it generally takes at least a year for a body to be fully skeletonized or reduced to disarticulated bones [22].

So, the disjunctive conjunctions introduce into the utterance the element which serves either for explanation or correction.

\section{Conclusions}

The cognitive study of language units reveals that the human mind comprehends different situations of reality, namely, those of choice, deficient knowledge, alternation, distribution, and motivation, and performs different mental operations, such as enumeration, approximation, and addition by means of the alternative relation which plays a significant role in creating the picture of the world. The elements of the world picture organized by the alternative relation are rendered in the English language by the syntactic structures consisting of the language elements of various complexity joined by the disjunctive conjunctions. Such a wide application of the alternative relation by the human mind is determined by the modification or neutralization of the inherent meaning of the conjunctions or, either... or in the grammatical and lexical environment which enables 
them to convey all the above-mentioned situations and mental operations. The research confirms the importance of the alternative relation for the cognition which in its turn determines the significance of the syntactic structures with the disjunctive conjunctions for the communication, including cross-cultural one, as they can be used for different communicative purposes. It must be taken into account in teaching English as a foreign language. The ability of the disjunctive conjunctions to be subjected to the semantic changes in the context can be also very helpful in translation and interpretation.

\section{References}

1. N. Boldyrev, Proceedings of the Philological Readings, 1-8 (2020)

2. N. Boldyrev, O. Dubrovskaya, Ilha do Desterro, 69 (1), 173-182 (2016), doi: 10.5007/2175-8026.2016v69n1p173

3. K. Fischer, Language and Cognition, 7(4), 563-588 (2015)

4. T. Tenbrink, Language and Cognition, 7(1), 98-137 (2015)

5. N. Mahpeykar, A. Tyler, Language and Cognition, 7(1), 1-35 (2015)

6. N. Besedina, S. Stepanenko, O. Fedotova, Y. Sherstyokova, Journal of Language and Literature, 5(3), 83-88 (2014), doi: 10.7813/j11.2014/5-3/15

7. M. Kulkova, A. Shaidullina, XLinguae, 13(2), 50-59 (2020), doi: 10.18355/XL.2020.13.02.04

8. Z. Kövecses, Language and Cognition, 9(1), 121-155 (2017)

9. I. Solodilova, I. Gulyayeva, L. Ivanova, Proceedings of the Philological Readings, 590599 (2020)

10. E. Murugova, The European Proceedings of Social and Behavioural Sciences, 416-425 (2018), doi 10.15405/epsbs.2018.04.02.59

11. N. Stolova, Cognitive Linguistics and Lexical Change: motion verbs from Latin to Romance, 261 (2015)

12. S. Kuzmina, Moderna Sprak, 107(2), 99-114 (2013)

13. N. Sklyarova, International Journal of Cognitive Research in Science, Engineering and Education, 1(2), 45-50 (2013)

14. Y. Wang, L. Wei, Language and Cognition, 11(4), 527-554 (2019)

15. S. Belkhir, Cognition and Language Learning, 157 (2020)

16. D. Li, Victoria L. C. Lei, Y. He, Researching Cognitive Processes of Translation (New Frontiers in Translation Studies), 201 (2019)

17. T. Mikheeva, E. Murugova, SHS Web of Conferences. The Conference Proceedings, 07003 (2019)

18. S. Pesina, T. Abramzon, S. Rudakova, et al., Laplage em Revista, 6, 330-337 (2020), doi: 10.24115/S2446-622020206Extra-C673p.330-337

19. M. Romano, M. D. Porto, Exploring discourse strategies in social and cognitive interaction, 299 (2016)

20. O. Shmeleva, M. Zheltukhina, G. Slyshkin, et al., Propositos y representaciones, 8 (52), e798 (2020), doi: 10.20511/pyr2020.v8nSPE2.798

21. British National Corpus. Retrieved: October 15, 2020, http://www.natcorp.ox.ac.uk/

22. The Corpus of Contemporary American English. Retrieved: October 15, 2020, http://www.corpus.byu.edu/coca/ 
23. N. Sklyarova, International Journal of Cognitive Research in Science, Engineering and Education, 2(2), 43-48 (2014) 